\title{
Safeguarding our Future: Minimizing Litigations in Maternity Care
}

\author{
Karki C \\ Department of Obs/Gyn, Kathmandu Medical College
}

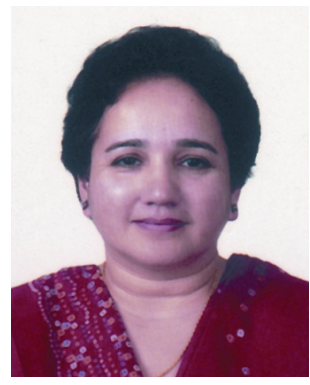

There were the days when common people used to obey every instructions, decisions and advice of doctors with closed eyes and mind! Doctors were placed high up in the social status and were looked upon as God. Today Services provided by the doctors have become the subject matter of judicial review time and again. 'Duty to take care', 'standard of care', 'negligence' etc has been defined by the law. Consumer protection act is now popularly been utilized and consumers are well aware of process of claim.

Money paid out for clinical negligence now accounts for a sizeable part of National Health Service spending in countries like USA, UK and Australia. ${ }^{1}$ Medical litigations have increased significantly in all medical specialties but Ob/Gyn are worst among the sufferers. This is because Ob/Gyns usually deal with young and otherwise healthy women (pregnancy is physiology not pathology). Probably the community is not yet aware of the fact that practicing obstetrics without complication is not possible. Unpredictability is the rule rather than exception in obstetrics. Even when timely and dynamic decisions are taken, some of the unanticipated complications are potentially serious and can prove fatal at times.

More than $50 \%$ of medical malpractice claims in USA are related to obstetrical problems. According to the American College of Obstetricians and Gynecologists (ACOG 1990), $78 \%$ of Ob/Gyns have been sued once and $37 \%$ have been sued three or more times. ${ }^{1}$ This type of litigation problem is rapidly spreading all over the world and Nepal is no longer an exception.

Errors do occur during service provision at times due to various factors like fatigue, overwork, emotional stress, noise or similar distractions. Error may be in the form of slips (e.g. pouring a salt packet into coffee instead of a

sugar packet) or mistakes (e.g. misdiagnosing right upper quadrant abdominal pain associated with HELLP syndrome in pregnancy as cholecystitis or pyelonephritis). Therefore high priority should be set in the system to reduce error and thus to improve the safety.

Legal problems may arise due to any events in obstetrics during antenatal, intra-natal and postnatal periods, intranatal events being most common.

Diagnostic error is now the second leading cause of all professional liability claims in United States. Negligent antepartum care, inadequate genetic counseling, negligent management of pregnancy related complications, negligent monitoring of the fetus during labor, improper use of oxytocics, improper diagnosis and management of abnormal labor, negligent management of delivery complications and improper timing of caesarean delivery are eight most common allegations made in maternity claims.

According to Physician Insured Association of America (PIAA), birth asphyxia was one of the most common among charges made to obstetricians which resulted in indemnity payment. $^{2}$ This report shows that $49 \%$ of brain damaged infant claims resulted in indemnity payment and it has identified three high risk obstetrical areas for liability -

1. Delay in deciding or performing LSCS due to various intended and unintended reasons and this delay has lead to brain damage in the fetus.

2. Neonatal injury sustained during forceps delivery is found as one of the most common reason for medical litigation.

3. Delay in Identification and management of Shoulder dystocia.

\section{CORRESPONDENCE}

Chanda Karki

Professor and Head

Department of Obstetrics and Gynaecology

Kathmandu Medical College, Kathmandu

Phone: 9851026793

Email: chandabkarki@hotmail.com 
Failure to provide proper antenatal care by the service provider or due to inadequate infrastructural support or many other similar areas in obstetrics may invite complications and litigations. According to WHO poorly managed births are implicated in the deaths of 585,000 mothers and as many as four million newborns internationally each year. ${ }^{3}$

Consent issues, vicarious liability, improper and incomplete history taking, physical examination or work up, faulty record keeping and communication gap between service providers are some of the secondary risk factors. Such problems may arise due to service providers' casualness and negligent attitude. Inability or error in diagnosing congenital anomalies, failure to give advice or giving wrong advice in this regard mostly can give rise to litigation problems.

Postpartum hemorrhage, anal sphincter injury, genital fistula, shoulder dystocia, vaginal birth after caesarian section and any other reasons for maternal/perinatal mortality and morbidity are also other sources of obstetric litigations.

People and society have very high expectations from medical science. People want everything perfect and always expect a good outcome from the service and if there is any deviation from "perfect" they find it difficult to accept and think about taking legal action. In obstetrics, service provider deals with physiology not pathology. Unlike during the diseased conditions, since conception till delivery whole family remains in a happy and jolly mood and prepares everything for celebrating the happy and positive outcome at the end of nine months. Any deviation from this can create a big emotional havoc. It becomes absolutely unacceptable to the party and in almost all cases they do not appreciate the genuine and tiring efforts made by the service provider to save the patient and they have no empathy for the tremendous stress of the provider. Vindictive attitude of the party is also an important underlying cause.

Sometimes intense grief also finds its outlet through anger. Service providers not caring to explain the gravity of the patient's condition well in advance or thoughtless remarks from the service providers can also be a triggering factor for this. Financial benefit is usually a silent motive. ${ }^{2}$

Obstetricians are gradually declining towards defensive medical practice due to which cost of defensive insurance is also rising and obviously health care service is also being increasingly expensive.

Service providers also suffer from great emotional stress which leads to condition like depression, matrimonial disaster, premature retirement etc. which again affects health care system negatively. ${ }^{4}$
On the other hand, medico legal problems also help to maintain the standard of health care. Service providers feel more accountable to the clients, read more and practice medicine to high standard because of the fear of litigation.

Consumer's protection act is in vogue nowadays in the country. Therefore it is important today to take precautions to minimize such medico legal liabilities. Whenever the health care providers decide to treat a patient they must realize that they are entering into an unwritten contract which means they are offering the patient to cure or relieve them with their skill and diligence. ${ }^{5}$ The court expects the health care providers to offer the skills of a reasonable physician. If they fall below standard they are held to be negligent in their duties and hence are liable to pay compensation. Therefore to avoid medico legal litigation health care providers have to always keep in mind the standards of practice.

Service providers not only need to be qualified and registered with medical council, they also need to be updated in their knowledge and skill. This is the overall responsibility of any health institution to upgrade the service providers on regular basis by facilitating to attend the subject related conferences, seminars, workshops and training programs. Adequately trained service provider can minimize the chance of litigation not only by providing quality service but can also take all the measures to minimize it and if needed can defend himself/herself ${ }^{5}$.

Service providers need to update themselves continuously about latest research and publications in various forms. Guidelines are often cited as standard or accepted practice. $^{6}$ Therefore service providers should be well acquainted with institutional, national and international guidelines and protocols. Listening to seniors and mentors as to what they are trying to teach or coach them for providing quality and complete care of the patients is also a strong means to minimize litigation effect. If the service provider has to play an advisory role to policymakers or they themselves are at policy making level, they need to be aware about the needs of community people, different levels of health care providers and about the current views of local and central level of policy makers and leaders. Allegation and accusation may be filed against doctors in Nepal Medical Council which may take disciplinary action. Medical profession is now under the preview of consumer protection act. ${ }^{7,8}$

Behavior and communication are two very important aspects of doctor patient relationship ${ }^{6}$. Health care providers, especially doctors and nurses need to behave according to the expectations of the patient and her party. Patients nowadays are educated and knowledgeable. They expect a descent and logical behavior from the service providers, transparency and rationale of the treatment received. Uncertainties are always going to be there in 
obstetrical practice and therefore mishaps are unavoidable at times. Proper communication with the patients and their party to regularly counsel in simple language is necessary. Antenatal education and information is important. Parties usually sue the doctors when they do not get proper explanation as to what went wrong. Service provider also need to make sure that patients understand the explanations and proposed course of action. It is always wise to spot trouble as early as possible and ask for help. For correct diagnosis it is important to listen carefully with an open mind to patients, medical colleagues, nursing and paramedic staffs

In spite of providing best care and maintaining best of communication sometimes health care providers might have to face medico legal litigation. In this situation the documentation of the treatment becomes the proof of the standard of care. Patients or clients case charts then becomes the "mirrors of health care provider's action" in the court of law. ${ }^{4}$ Consent forms, daily records, discharge summaries, certificates etc are the only defense shields for them and all health care providers must learn to maintain them properly.

No matter how much careful health care providers or institutions are, complications are inevitable in obstetrics. Medical litigation will continue to be filed now and then as long as we continue to provide the service. Therefore securing oneself with professional insurance scheme may be the ultimate remedy for litigation problems. Health care providers personally as well as the institutes or health facilities need to have cover of a good insurance policy which will take care of compensation in case of adverse outcome.

These days people related to health care service worldwide are concerned about the litigation problems and therefore have defined a process of protecting the patient, doctor and facility from legal liability. This process has been given the name of risk management. ${ }^{6}$ The development of risk management program is now a necessity in each unit for improving patient care and reducing medico legal risks and cost.

Risk management involves development of the strategies to optimize the patients well being, to prevent or limit health risk to the patients as well as legal risk to care giver.

Within a health care context risk management has four important components as follows:

\section{Risk identification}

It is the first step in risk management. Besides many sources of information, history plays an important role to understand the risk involved in health care. Risk factor should be clearly displayed on the front page of the chart and antenatal record. Pre-conception identification of issues related to poor nutrition, smoking, alcohol use is crucial. Identification and planned management of prepregnancy chronic hypertention, diabetes etc., careful dating of pregnancy and identifying prior obstetric complications or genetic risks or infections are crucial factors.

\section{Risk analysis}

Analyzing several sources of data provide a rich source of information that is used in the analysis phase. Incidents are analyzed in order to establish how often they happen, how it is treated, under what circumstances it occurred and what their effects might be. This helps to concentrate and focus attention on getting these aspects of care right. This analysis on a grand scale is used at hospital or state level to inform strategies and initiatives across services. National professional societies can play an important role in this regard.

\section{Risk control}

After risk identification and analysis, it is considered how they can be avoided, reduced, transferred or eliminated. This can be through physical and systems controls, but also requires an understanding of how doctors interact with patients and members of the multidisciplinary team. Technical and human errors play a large part in incidents and adverse events, and can often be pinpointed so that they can be controlled. Some risk can never be completely eliminated, but likelihood of its occurrence could be reduced. There are four ways of coping with risk: avoid, reduce, transfer and retain.

\section{Risk funding}

We need to have the cover of a good insurance policy which will take care of compensation in case of adverse outcome. Unlike in a big set up where the risk management department takes the responsibility of the risk, smaller set ups like ours need to realize that here doctor himself/ herself should be acting as his/her own risk managers.

To conclude, service providers are aware of Hippocratic oath which states that "I will keep patients from harm and injustice". They constantly follow this motto and utililise their knowledge and skill to treat the patient but complications do occur at times resulting in harm to both the patients and service providers. Unintended outcomes therefore are part of reality in health care. Errors also may happen, but one should realize that to err is human and to learn from error is humane. If unintended outcomes result from errors they are considered to be preventable. Errors are therefore an important starting point to improve patient safety. Errors should be continuously analyzed, discussed, confessed and thereafter measures should be continuously taken to enhance the skill and knowledge, bring positive change in attitude, behavior and communication skill of the service providers. This will help them to recognize errors before they become adverse events. Community 
awareness programs should also be there to make people realize the limitation of medical science and to make them understand the difference between complications and negligence. Service providers should be aware about the risk management issues either by themselves or through

\section{REFERENCES}

1. Bewly S. Medical law made easy. Progress in Obstetrics and Gynaecology 13. Edited by John Studd.1-10.

2. Mukherjee GG. Medico legal aspect of obstetric practice. Principles and practice of Obstetrics and Gynaecology for postgraduates. 2003. 2nd ed. Edited by U B Saraiya et al.580-3.

3. Atwood LA, Macken K. Safety in Maternity care. Advanced Life support in Obstetrics (ALSO). Published by American Academy of family Physician 2001. 4th ed .Edited by James R Damos \& Steven $\mathrm{H}$ Eisinger Section L.1-13.

4. Puxon M. Medico legal aspect of obstetrics and Gynaecology. Progress in Obstetrics and Gynaecology 4. Edited by John Studd. $11-21$ the facilities so that that they do not fail to practice the guiding principles of risk management like compassion, communication, competence, charting and confession.

5. Naftalins NJ.et al. Medico legal issues and clinical risks: how clinical governance improves care. Gynaecology. 3rd ed. Edited by Robert Shaw et al.973-85.

6. Gupte S. Minimising litigation in Obstetrics and Gynaecology. Chapter 37. ObGyn highlights: an evidence based review published by AICC RCOG Eastern zone \& Ministry of Health and family welfare, Government of India. 2006. Edited by Alokendu Chaterjee.369-73.

7. Nepal Government Ministry of Law and justice. Nepal Aain Sangraha- Part 8 BS 2068.

8. Shrestha GB. Niyam Sangraha: Ek parichaya 2068. Part -2 Published by Pairabi Prakashan. 